Article

\title{
The Effect of Compactness on Laser Cutting of Cathode for Lithium-Ion Batteries Using Continuous Fiber Laser
}

\author{
Dongkyoung Lee ${ }^{1} \mathbb{D}$, Byungmoon $\mathrm{Oh}^{1}$ and Jungdon Suk ${ }^{2, *}$ \\ 1 Department of Mechanical and Automotive Engineering, Kongju National University, Cheonan 31080, \\ Korea; ldkkinka@kongju.ac.kr (D.L.); obm0923@gmail.com (B.O.) \\ 2 Energy Materials Research Center, Advanced Materials Division, KRICT, 141 Gajeong-ro, Yuseong-gu, \\ Daejeon 305-600, Korea \\ * Correspondence: jdsuk@krict.re.kr; Tel.: +82-42-860-7335; Fax: +82-42-860-7200
}

Received: 1 December 2018; Accepted: 24 December 2018; Published: 8 January 2019

\begin{abstract}
Lithium-Ion Batteries (LIB) are growing in popularity for many applications. Much research has been focusing on battery performance improvement. However, few studies have overcome the disadvantages of the conventional LIB manufacturing processes. Laser cutting of electrodes has been applied. However, the effect of electrodes' chemical, physical, and geometrical characteristics on the laser cutting has not been considered. This study proposes the effect of compression of cathode on laser cutting for lithium-ion batteries. The kerf width and top width of the specimens with laser irradiation are measured and the material removal energy is obtained. Observations of SEM photographs and absorptivity measurements are conducted. Increasing volume energies causes logarithmic increases in the kerf and top width. It is observed that the compressed cathode forms a wider kerf width than the uncompressed cathode under the same laser parameters. The top width of the uncompressed cathode is wider than the uncompressed cathode. The compression has a favorable effect on uniform cutting and selective removal of an active electrode.
\end{abstract}

Keywords: laser cutting; lithium-ion battery; compression; cathode; continuous fiber laser

\section{Introduction}

Lithium-ion batteries (LIBs) has been used actively due to their advantages such as a high energy density and low self-discharge compared to nickel-cadmium and lead-acid batteries. LIBs are also growing in popularity for aerospace, electric vehicle, and military applications. Thus, much research focusing on performance improvement has been actively carried out [1-10]. However, few studies have overcome the disadvantages of the conventional LIB manufacturing processes. Among the many manufacturing technologies, laser cutting is actively and successfully replacing the conventional cutting processes due to its advantages [11-38]. Lee et al. [16-18] applied the mathematical model to understand multi-physical phenomena in the laser cutting process for lithium-ion batteries. Furthermore, experimental studies were conducted to investigate the physical phenomena and interaction characteristics during laser cutting of electrode for lithium-ion batteries $[11,13-15,18]$. Lutey et al. [30,39] used both a continuous (CW) and pulsed laser to cut electrodes for lithium iron phosphate battery electrodes. The process efficiency and quality were characterized and found that the cutting efficiency increases with shorter pulses, higher velocity, and shorter wavelength [30,39]. Luetke et al. [40] compared a CW and pulsed laser to evaluate the cut quality by defining frazzling and clearance widths. The influences of pulse overlap on cut quality for the laser cutting of electrodes for lithium-ion batteries were studied by Reincke et al. [41] They evaluated the heat affected zone and delamination width. Jansen et al. [42] applied laser cutting on pure lithium metal foils since the 
lithium metal anodes are hardly separated by die cutting for mass production. Thus, they presented the remote laser cutting to show the potential to separate anodes with high quality. Demir et al. [34] compared the cut quality of laser cutting of lithium-ion electrodes with green and infrared pulsed lasers and found that the green laser provided a clearance width below $20 \mu \mathrm{m}$ and the infrared laser provided the high-productivity criterion.

The electrodes' chemical, physical, and geometrical characteristics are important and most critical parameters during laser cutting. However, no such factors have been considered. Therefore, this study proposes the effect of compression of cathode on laser cutting for lithium-ion batteries. First, materials, experiments, and measurement methods are described. Second, the laser cutting characteristics using compressed and uncompressed cathodes are analyzed and compared. Finally, the conclusions are presented.

\section{Material, Experiment, and Measurement}

Single-mode Quasi-CW Ytterbium Fiber Laser (IPG YLM-200/2000-QCW) was used with CW mode. The $M^{2}$ value was 1.05 . The wavelength was $1070 \mathrm{~nm}$ and the maximum average output power was $250 \mathrm{~W}$. The vertical distance from the F-theta lens to the surface was set to be $100 \mathrm{~mm}$. The laser spot size at focus was $23 \mu \mathrm{m}$. The width of the cathode sample was $30 \mathrm{~mm}$, and the cutting distance was $20 \mathrm{~mm}$ horizontally so that even though the laser cut sample was completely separated, the rest of the sample remains attached. Both ends of the specimen were held by clamps so that the space was formed between the specimen and the table to prevent any possible effects such as heat conduction and material attachment from the table, as shown in Figure 1. The laser output power used for the experiments were varied from $50 \mathrm{~W}$ to $250 \mathrm{~W}$ at intervals of $50 \mathrm{~W}$ and the laser scanning speed was varied from $500 \mathrm{~mm} / \mathrm{s}$ to $5000 \mathrm{~mm} / \mathrm{s}$ at an interval of $500 \mathrm{~mm} / \mathrm{s}$. These are shown in Table 1 . The volume energy depending on the output power and scanning speed is shown in Figure 1.

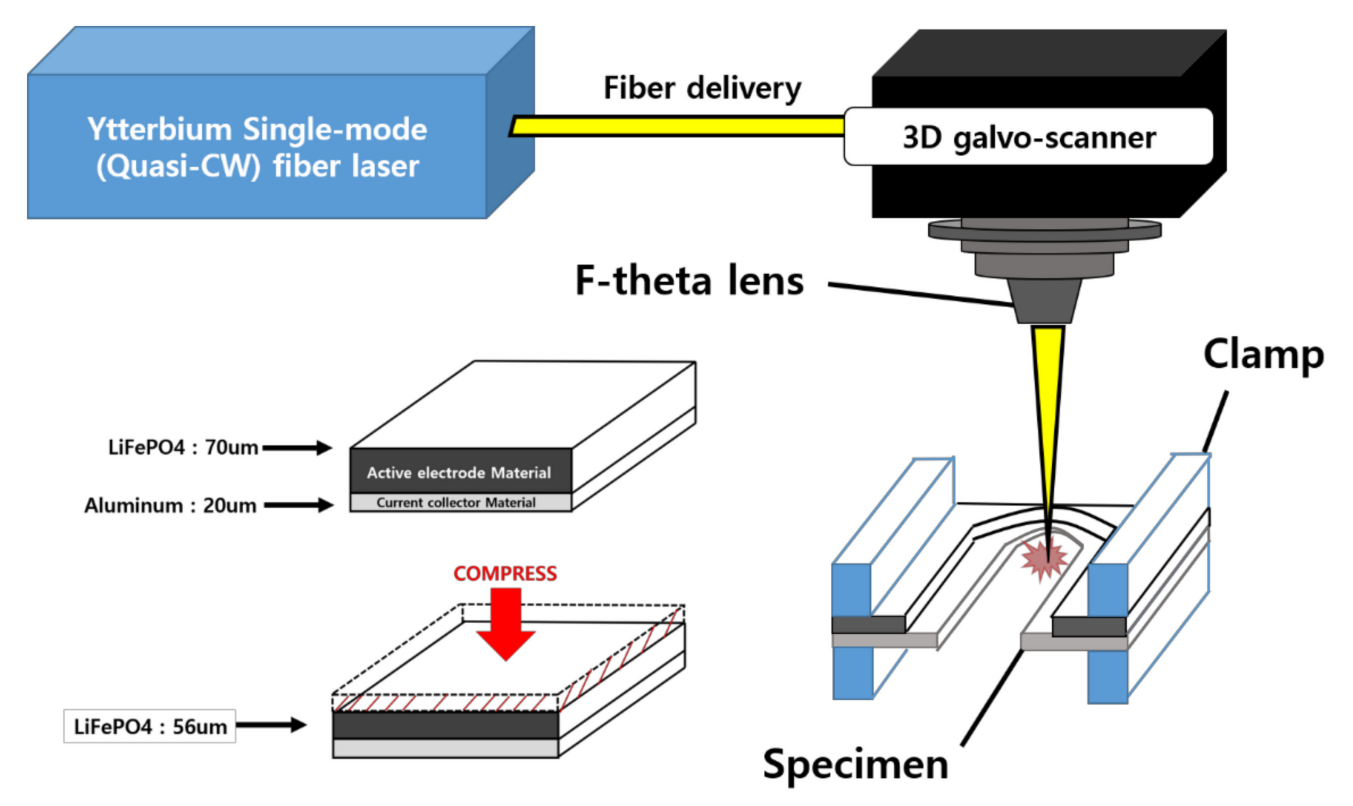

Figure 1. Cathode sample and Experimental set-up.

Table 1. Laser power, speed, and volume energy used for the experiments.

\begin{tabular}{cccc}
\hline$\#$ & Power $(\mathbf{W})$ & Speed $(\mathbf{m m} / \mathbf{s})$ & Volume Energy $\left(\mathrm{J} / \mathbf{m}^{\mathbf{3}}\right)$ \\
\hline $50,100,150,200,250$ & $500,1000,1500,2000,2500,3000,3500,4000$, & $4.348 \times 10^{5} \sim 2.174 \times 10^{7}$ \\
\hline
\end{tabular}


Compressed and uncompressed cathode samples were used. The compressed cathode was coated with a $76 \mu \mathrm{m}$-thick active electrode material on a $20 \mu \mathrm{m}$-thick current collector and then was compressed from $76 \mu \mathrm{m}$ to $56 \mu \mathrm{m}$, as shown in Figure 1. The uncompressed sample was coated with a $70 \mu \mathrm{m}$-thick active electrode material on a $20 \mu \mathrm{m}$-thick current collector. The detailed information of the materials was summarized in Table 2. It should be noted that the total thickness of this cathode was relatively thin for high power applications. The active electrode material consists of $90 \%$ of $\mathrm{LiFePO}_{4}$, $5 \%$ SuperC65 (Conducting agent), and 5\% of polyvinylidene fluoride (binder). The current collector is aluminum. The working electrode was formulated by the mixing of active materials, conductive carbon materials and PVDF binder with a controlled amount of NMP solvent. After slurry coating on $\mathrm{Al}$ current collector, the electrode was dried at $120^{\circ} \mathrm{C}$ in a convection oven for $6 \mathrm{~h}$ and then dried at $90{ }^{\circ} \mathrm{C}$ in a vacuum oven for $24 \mathrm{~h}$ before use.

Table 2. Material information of cathode.

\begin{tabular}{ll}
\hline \multicolumn{1}{c}{ Category } & \multicolumn{1}{c}{ Cathode Information } \\
\hline Structure & One-side sandwich \\
Active electrode Material & $\mathrm{LiFePO}_{4}$ \\
Active electrode Thickness (Uncompressed) & $70[\mu \mathrm{m}]$ \\
Active electrode Thickness (Compressed) & $70[\mu \mathrm{m}] \rightarrow 56[\mu \mathrm{m}]$ \\
Binder & Polyvinylidene fluoride \\
Conducting agent & SuperC65 \\
Solution & $N-$ Menthy-2pyrrolidone \\
Current Collector Material & Aluminum \\
Current Collector Thickness & $20[\mu \mathrm{m}]$ \\
\hline
\end{tabular}

A Scanning Electron Microscope (SEM, VEGA3, TESCAN, Brno, Czech Republic) was utilized to observe the cut surface and cross-section of the laser cut sample. After the laser cutting, the sample is cut into $2 \times 2 \mathrm{~cm}$ size for SEM analysis. Energy-dispersive X-ray spectroscopy (EDX) analysis was conducted to measure the composition variation. Furthermore, the absorption rates were measured by UV-VIS spectroscopy (SolidSpec-3700, Shimadzu, Kyoto, Japan).

The kerf, top, and melting widths were measured based on the previously published papers [12-14]. The energy used in cutting to melt and evaporate the cathode can be derived from the measured widths and shown in Figure 2. Since the melting width rarely occurred, the melting width is set equal to the kerf width. The volume removed by melting and evaporation are expressed by

$$
\begin{aligned}
& V_{\text {melt }_{A E}}=V_{\text {evap }_{A E}}=l_{g} d_{A E} W_{t o p} \\
& V_{\text {melt }_{C C}}=V_{\text {evap }_{C C}}=l_{g} d_{C C} W_{\text {kerf }}
\end{aligned}
$$

where $d_{A E}$ is the thickness of an active electrode (AE) material, and $d_{C C}$ is the thickness of a current collector (CC). The energy required to evaporate the given volume is expressed by

$$
\begin{gathered}
E_{\text {evapn }}=m_{s_{n}}\left\{c_{s_{n}} \cdot\left(T_{\text {melt }_{n}}-T_{0}\right)+L_{\text {mel }_{n}}\right\}+m_{l_{n}}\left\{c_{l_{n}} \cdot\left(T_{\text {evap }_{n}}-T_{\text {melt }_{n}}\right)+L_{\text {evap }_{n}}\right\} \\
=\rho_{s_{n}} V_{\text {melt }_{n}}\left\{c_{s_{n}} \cdot\left(T_{\text {melt }_{n}}-T_{0}\right)+L_{\text {melt }_{n}}\right\} \\
+\rho_{l_{n}} V_{\text {evap }_{n}}\left\{c_{l_{n}} \cdot\left(T_{\text {evap }_{n}}-T_{\text {melt }_{n}}\right)+L_{\text {evap }_{n}}\right\},(n=\mathrm{CC} \text { and } \mathrm{AE})
\end{gathered}
$$

where $m$ is the mass, $c$ is the specific heat, $\rho$ is the density, $T_{m e l t}$ is the melting temperature, $T_{\text {evap }}$ is the evaporation temperature, $T_{0}$ is the ambient temperature, $L_{\text {melt }}$ is the latent heat of melting, and $L_{\text {evap }}$ is the latent heat of evaporation. In addition, subscription s and $l$ indicates solid and liquid, respectively. Subscription $n$ can be a current collector (CC) or active electrode materials (AE). The total energy (E) used to remove a cathode is obtained as follows:

$$
E=E_{\text {evapAE }}+E_{\text {evap } C C}
$$






Figure 2. Definition of areas for cutting efficiency.

If we rewrite the equation with measurable kerfs, then it can be written as

$$
\begin{aligned}
E \quad & =\rho_{s_{A E}} l_{g} d_{A E} W_{\text {top }}\left\{c_{s_{A E}} \cdot\left(T_{\text {melt }_{A E}}-T_{0}\right)+L_{\text {melt }_{A E}}\right\} \\
+ & \rho_{l_{A E}} l_{g} d_{A E} W_{\text {top }}\left\{c_{l_{A E}} \cdot\left(T_{\text {evap }_{A E}}-T_{\text {melt }_{A E}}\right)+L_{\text {evap }}{ }_{A E}\right\} \\
& +\rho_{s_{C C}} l_{g} d_{A E} W_{\text {kerf }}\left\{c_{s_{C C}} \cdot\left(T_{\text {melt }_{C C}}-T_{0}\right)+L_{\text {melt }_{C C}}\right\} \\
+ & \rho_{l_{C C}} l_{g} d_{A E} W_{\text {top }}\left\{c_{l_{C C}} \cdot\left(T_{\text {evap }_{C C}}-T_{\text {melt }_{C C}}\right)+L_{\text {evap }}\right\}
\end{aligned}
$$

Since material properties of $\mathrm{LiFePO}_{4}$ are not fully available, those were derived by the law of

\begin{tabular}{|c|c|c|c|c|c|}
\hline Property & $\mathrm{Fe}$ & $\mathbf{P}$ & $\mathbf{L i}$ & $\mathrm{O}$ & $\mathrm{LiFePO}_{4}$ \\
\hline Melting temperature & $1809.15(\mathrm{~K})$ & $317.3(\mathrm{~K})$ & $453.85(\mathrm{~K})$ & $54.36(\mathrm{~K})$ & $744.745(\mathrm{~K})$ \\
\hline $\begin{array}{l}\text { Normal boiling } \\
\text { temperature }\end{array}$ & $3134.15(\mathrm{~K})$ & $553.65(\mathrm{~K})$ & $1609.15(\mathrm{~K})$ & $90.20(\mathrm{~K})$ & $1325.56(\mathrm{~K})$ \\
\hline Critical point temperature & $8500(\mathrm{~K})$ & $994(\mathrm{~K})$ & $3223(\mathrm{~K})$ & $154.59(\mathrm{~K})$ & $3408.62(\mathrm{~K})$ \\
\hline Liquid density & $2986.5\left(\mathrm{~kg} / \mathrm{m}^{3}\right)$ & $740\left(\mathrm{~kg} / \mathrm{m}^{3}\right)$ & $512.5\left(\mathrm{~kg} / \mathrm{m}^{3}\right)$ & $1141\left(\mathrm{~kg} / \mathrm{m}^{3}\right)$ & $1687.91\left(\mathrm{~kg} / \mathrm{m}^{3}\right)$ \\
\hline Solid density & $7800\left(\mathrm{~kg} / \mathrm{m}^{3}\right)$ & $1820\left(\mathrm{~kg} / \mathrm{m}^{3}\right)$ & $533.4\left(\mathrm{~kg} / \mathrm{m}^{3}\right)$ & $1535\left(\mathrm{~kg} / \mathrm{m}^{3}\right)$ & $3764.65\left(\mathrm{~kg} / \mathrm{m}^{3}\right)$ \\
\hline Latent heat of vaporization & $247,000(\mathrm{~J} / \mathrm{kg})$ & $21,200(\mathrm{~J} / \mathrm{kg})$ & $22.73 \times 10^{6}(\mathrm{~J} / \mathrm{kg})$ & $0.2131 \times 10^{6}(\mathrm{~J} / \mathrm{kg})$ & $3.379 \times 10^{6}(\mathrm{~J} / \mathrm{kg})$ \\
\hline Latent heat of fusion & $6,260,000(\mathrm{~J} / \mathrm{kg})$ & $392,000(\mathrm{~J} / \mathrm{kg})$ & $0.4339 \times 10^{6}(\mathrm{~J} / \mathrm{kg})$ & $13.88 \times 10^{3}(\mathrm{~J} / \mathrm{kg})$ & $116,362(\mathrm{~J} / \mathrm{kg})$ \\
\hline $\begin{array}{l}\text { Liquid constant-pressure } \\
\text { specific heat }\end{array}$ & $1642.35(\mathrm{~J} / \mathrm{kgK})$ & $2542.41(\mathrm{~J} / \mathrm{kgK})$ & $4225.8(\mathrm{~J} / \mathrm{kgK})$ & $1675.062(\mathrm{~J} / \mathrm{kgK})$ & $1946(\mathrm{~J} / \mathrm{kgK})$ \\
\hline $\begin{array}{l}\text { Solid constant-pressure } \\
\text { specific heat }\end{array}$ & 460.548 (J/kgK) & $770(\mathrm{~J} / \mathrm{kgK})$ & $3514.6(\mathrm{~J} / \mathrm{kgK})$ & $125.0046(\mathrm{~J} / \mathrm{kgK})$ & $519.56(\mathrm{~J} / \mathrm{kgK})$ \\
\hline Atomic weight & $55.845(\mathrm{~g} / \mathrm{mol})$ & $30.97(\mathrm{~g} / \mathrm{mol})$ & $6.941(\mathrm{~g} / \mathrm{mol})$ & $31.9988(\mathrm{~g} / \mathrm{mol})$ & $157.757(\mathrm{~g} / \mathrm{mol})$ \\
\hline
\end{tabular}
fraction and the material properties are shown in Table 3 . The material properties of aluminum can be found from Lee's paper [12].

Table 3. Material Properties of Fe, $\mathrm{P}, \mathrm{Li}, \mathrm{O}$, and $\mathrm{LiFePO}_{4}$.

\section{Results and Discussion}

First, the cut characteristics of compressed and uncompressed cathodes are investigated individually. The kerf and top widths are observed and analyzed in terms of scanning speed and volume energy. The melting widths are uncommonly observed so the analyses only considered with the kerf and top widths. Moreover, the cut surface of the sample and removal energy are observed. Second, the two types of cathodes were compared in terms of cutting configuration, cutting region, absorption rate, and composition changes.

\subsection{Width, Removal Energy, and Cut Surface of the Compressed Cathode}

Figure 3a shows the kerf width with respect to scanning speed (left) and volume energy (right). The kerf width is not formed with the laser power of $50 \mathrm{~W}$. When the scanning speed is faster than $2500 \mathrm{~mm} / \mathrm{s}$, the kerf width is not formed with the laser power of $100 \mathrm{~W}$. Increasing scanning speed from $500 \mathrm{~mm} / \mathrm{s}$ to $2500 \mathrm{~mm} / \mathrm{s}$ decreases the kerf width with the laser power of $100 \mathrm{~W}$. According to volume energy, volume energy greater than $9.628 \times 10^{10} \mathrm{~J} / \mathrm{m}^{3}$ is required to form the kerf width with the laser power of $100 \mathrm{~W}$. The kerf width is not formed with the laser power of $150 \mathrm{~W}$ when the scanning speed is faster than $4000 \mathrm{~mm} / \mathrm{s}$ so that it is noted that the volume energy greater than 
$9.026 \times 10^{10} \mathrm{~J} / \mathrm{m}^{3}$ is required to form the kerf width. For the laser power of $150 \mathrm{~W}, 200 \mathrm{~W}$ and $250 \mathrm{~W}$, the average kerf widths are bounded between $19 \mu \mathrm{m}$ and $37 \mu \mathrm{m}$ whenever the kerf width is observed. For the laser power of $200 \mathrm{~W}$ and $250 \mathrm{~W}$, the kerf width can be observed for all scanning speeds used in this study. The kerf width decreases almost linearly and two slopes are observed. One slope is observed from the scanning speed of $500 \mathrm{~mm} / \mathrm{s}$ to $1500 \mathrm{~mm} / \mathrm{s}$ and the other slope is observed from the scanning speed of $1500 \mathrm{~mm} / \mathrm{s}$ to $5000 \mathrm{~mm} / \mathrm{s}$.
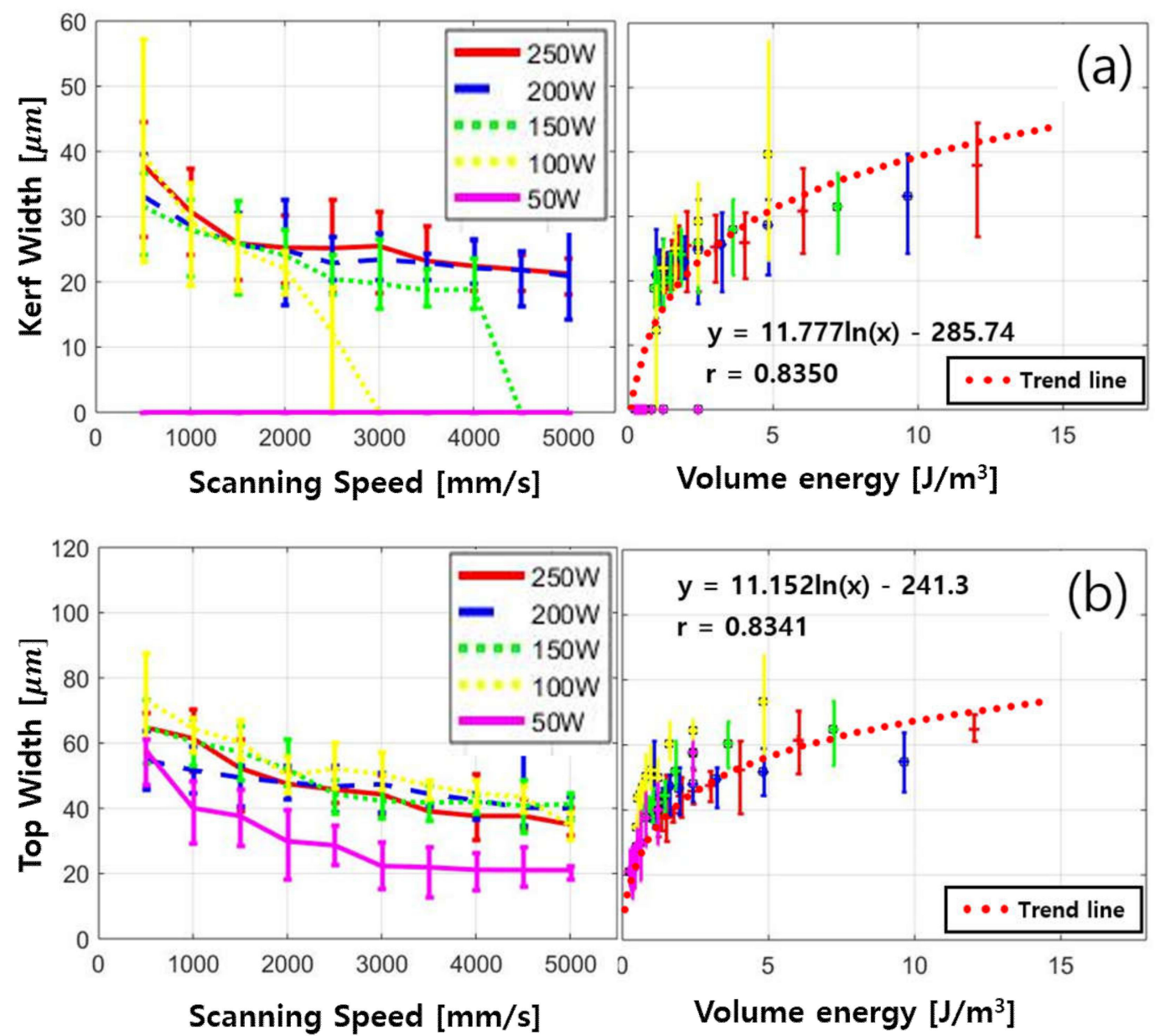

Figure 3. Comparison of (a) kerf width and (b) top width of the compressed cathode.

Figure $3 \mathrm{~b}$ shows the top width. Increasing scanning speed decreases the top width almost linearly with the laser power of $100 \mathrm{~W}, 150 \mathrm{~W}, 200 \mathrm{~W}$, and $250 \mathrm{~W}$, as well as the average top widths are bounded between $35 \mu \mathrm{m}$ and $70 \mu \mathrm{m}$. The top widths with the laser power of $50 \mathrm{~W}$ are slightly lower than top widths obtained at other laser powers. In addition, increasing the scanning speed from $500 \mathrm{~mm} / \mathrm{s}$ to $5000 \mathrm{~mm} / \mathrm{s}$ exponentially decreases the top width at the laser power of $50 \mathrm{~W}$.

Figure 3 also shows trend lines of volume energy (right). The trend line is obtained by regression analysis, which shows the relationship between the volume energy and the kerf width as well as the volume energy and the top width. The kerf width and the top width are dependent on the volume energies. Furthermore, increasing volume energy causes a logarithmic increase of the kerf width and the top width. The correlation coefficient $(r)$ of the kerf width and top width is 0.8350 and 0.8341 , respectively. Since it is rather close to 1 , it indicates that the variables are positively logarithmically related.

Figure 4 shows the average values of energy required to remove materials. This remove energy is obtained by Equation (5). Remove energy decreases exponentially as scanning speed is increasing for all laser powers. From the laser power of $100 \mathrm{~W}$ to $250 \mathrm{~W}$, the remove energy is similar to each other 
because the remove energy is measured based on the removed volume, as shown in Figure 2. One the other hand, the remove energy with the laser power of $50 \mathrm{~W}$ is significantly less than other cases. In this case, only the top width is measurable since only active electrode material is ablated. It is noted that required remove energy depends on interaction time when full cutting occurs.
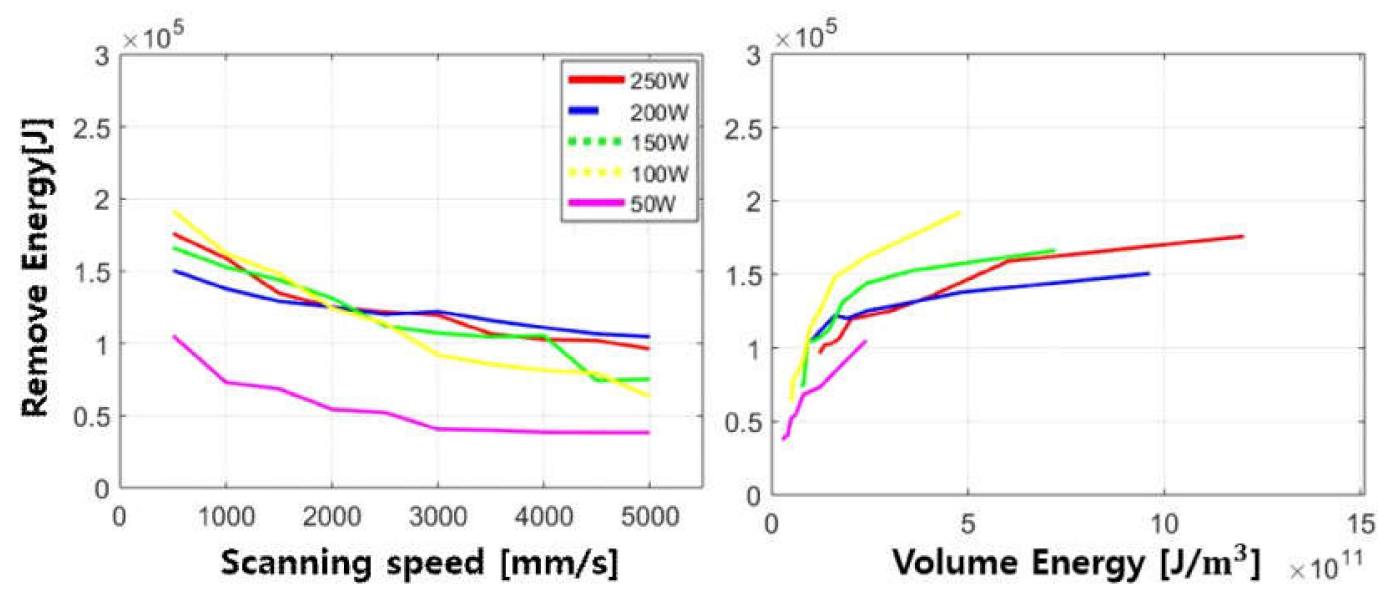

Figure 4. Comparison of removal energy for the compressed cathode.

Figure 5 shows SEM images of the compressed cathode cut at the laser power of $250 \mathrm{~W}$. Figure $5 \mathrm{a}, \mathrm{b}$ show the cathode top view and a cathode cross-section view, respectively. The melting width is not formed as shown in Figure 5a and it is invisible to all cut samples used in this study. Thus, no clearance width can be seen. More interesting characteristics can be observed in Figure 5b. At the scanning speed of $500 \mathrm{~mm} / \mathrm{s}$, a gap between the active electrode material and the current collector, which is delamination, is shown. It is inferred that the excessive heat induces a high recoil pressure so that the pressure pushes the active electrode material up and the amount of pressure generated is stronger than the peel strength between the active electrode material and the current collector.

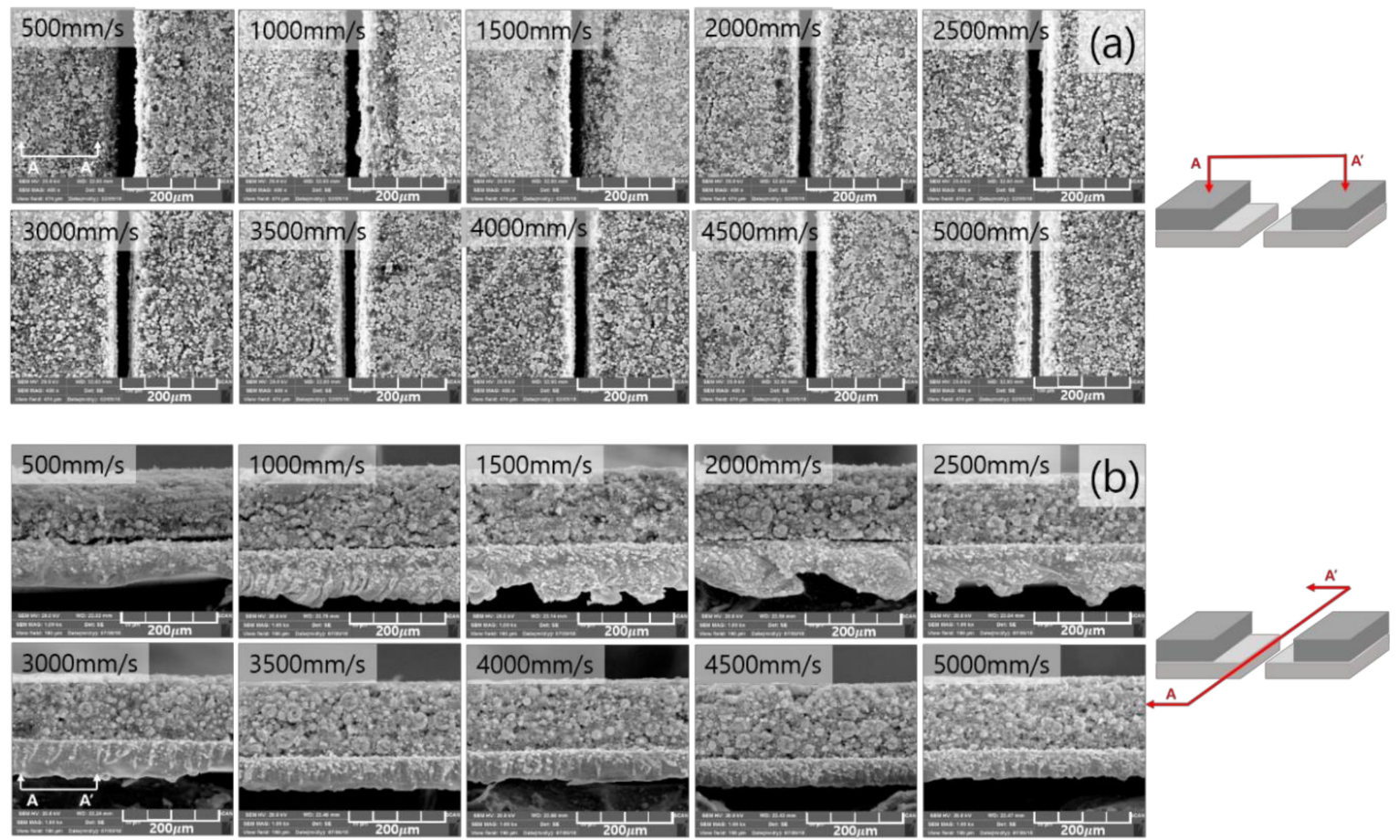

Figure 5. SEM images of compressed cathode with the laser power of $250 \mathrm{~W}$ : (a) Top view, (b) Cross-section. 
From the scanning speed of $1000 \mathrm{~mm} / \mathrm{s}$ to $2500 \mathrm{~mm} / \mathrm{s}$, the thickness of aluminum increases due to the re-solidified aluminum at the bottom of the specimen. The original thickness was $20 \mu \mathrm{m}$ but the thickness became about $23.5 \mu \mathrm{m}$ after the cutting. This may be caused by the aluminum melting and re-solidification so that the aluminum bead is formed. The melted aluminum is not fully removed during the cutting process, but flowed downward and solidified after the cutting process. Moreover, striation is clearly seen in the scanning speed of $1000 \mathrm{~mm} / \mathrm{s}$. This is an indication of flow fluctuation during the cutting process and sudden solidification. From all cut samples, the $\mathrm{LiFePO}_{4}$ in the form of spherical particles are found in the aluminum region. It may be because the $\mathrm{LiFePO}_{4}$, detached from the active electrode region due to the high pressure and high temperature, is formed during the cutting process. In addition, the detached $\mathrm{LiFePO}_{4}$ particles are embedded into the molten pool of aluminum. With the laser scanning speed of $500 \mathrm{~mm} / \mathrm{s}$ to $2500 \mathrm{~mm} / \mathrm{s}$, excessively high pressure and high temperature may lead to unstable laser cutting, or excessive cutting, characterized as delamination, re-solidified aluminum beads, striation, and embedded $\mathrm{LiFePO}_{4}$ particles. The characteristics observed above are clearly seen in Figure 6.

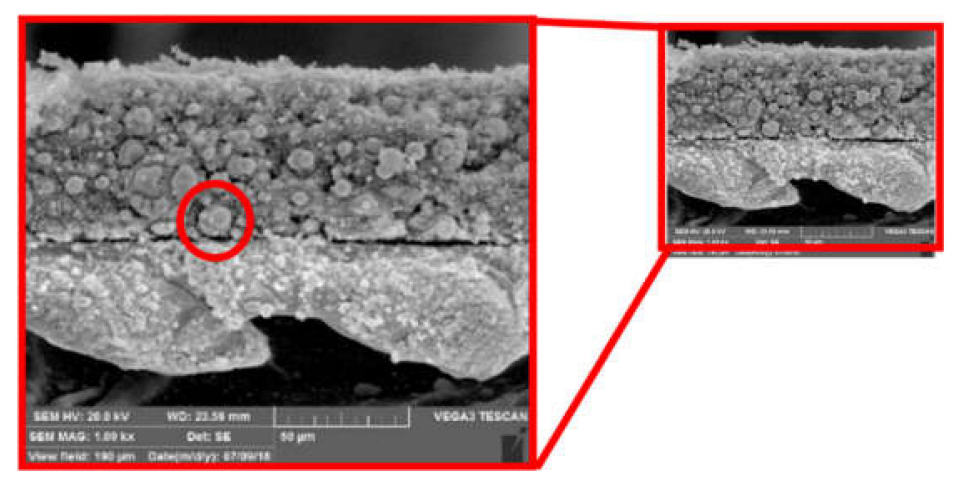

Figure 6. The cross-section of the compressed cathode with the scanning speed of $2000 \mathrm{~mm} / \mathrm{s}$.

At the scanning speed of $3000 \mathrm{~mm} / \mathrm{s}$, no delamination and aluminum beads were observed while striation marks and embedded spherical particles of $\mathrm{LiFePO}_{4}$ are still observed. At the scanning speeds between $3500 \mathrm{~mm} / \mathrm{s}$ and $5000 \mathrm{~mm} / \mathrm{s}$, high cut quality, or proper cutting, can be observed. No delamination, no striation, and no aluminum beads were formed while the $\mathrm{LiFePO}_{4}$ in the form of spherical particles are still observed.

\subsection{Width, Removal Energy, and Cut Surface of the Uncompressed Cathode}

Figure 7a shows the kerf width of the uncompressed cathode. Uncompressed cathodes have a narrower kerf width than compressed cathodes at the equal volume energy. The kerf width is not formed with the laser power of $50 \mathrm{~W}$. When the scanning speed is faster than $2500 \mathrm{~mm} / \mathrm{s}$, the kerf width is not formed at the laser power of $100 \mathrm{~W}$. Increasing the scanning speed from $500 \mathrm{~mm} / \mathrm{s}$ to $2500 \mathrm{~mm} / \mathrm{s}$ exponentially decreases the kerf width at the laser power of $100 \mathrm{~W}$. According to volume energy, the volume energy greater than $9.628 \times 10^{10} \mathrm{~J} / \mathrm{m}^{3}$ is required to form the kerf width with the laser power of $100 \mathrm{~W}$. When the laser power is the $150 \mathrm{~W}$, the kerf width is formed from the scanning speed of $500 \mathrm{~mm} / \mathrm{s}$ to $5000 \mathrm{~mm} / \mathrm{s}$. The kerf width exponentially decreases as the scanning speed increases from $500 \mathrm{~mm} / \mathrm{s}$ to $2500 \mathrm{~mm} / \mathrm{s}$ and then linearly decreases. When the kerf width decreases exponentially, kerf width shows a relatively greater variation. However, when the kerf width decreases linearly, its value is around $10 \mu \mathrm{m}$ with relatively little variation. When the laser power is the $200 \mathrm{~W}$ and $250 \mathrm{~W}$, a similar trend as observed from the kerf width with the laser power of $150 \mathrm{~W}$ is observed.

Figure $7 \mathrm{~b}$ shows the top width. Overall, the top widths decrease as the scanning speed increases. The top width with the laser power of $250 \mathrm{~W}$ and $200 \mathrm{~W}$ linearly decreases from the scanning speed of $500 \mathrm{~mm} / \mathrm{s}$ to $5000 \mathrm{~mm} / \mathrm{s}$. When the scanning speed is between $500 \mathrm{~mm} / \mathrm{s}$ and $1500 \mathrm{~mm} / \mathrm{s}$, almost similar values are observed. When the scanning speed is faster than $1500 \mathrm{~mm} / \mathrm{s}$, the variation of the top width 
is smaller than the variation of the top width from $500 \mathrm{~mm} / \mathrm{s}$ to $1500 \mathrm{~mm} / \mathrm{s}$. On the other hand, the top widths at the laser power of $200 \mathrm{~W}$ and $50 \mathrm{~W}$ linearly decrease from $500 \mathrm{~mm} / \mathrm{s}$ to $5000 \mathrm{~mm} / \mathrm{s}$. More interesting characteristics can be observed at the laser power of $150 \mathrm{~W}$. Increasing the scanning speed from $500 \mathrm{~mm} / \mathrm{s}$ to $1500 \mathrm{~mm} / \mathrm{s}$ decreases the top width exponentially. Also, increasing the scanning speed from $2000 \mathrm{~mm} / \mathrm{s}$ to $5000 \mathrm{~mm} / \mathrm{s}$ linearly decreases the top width.
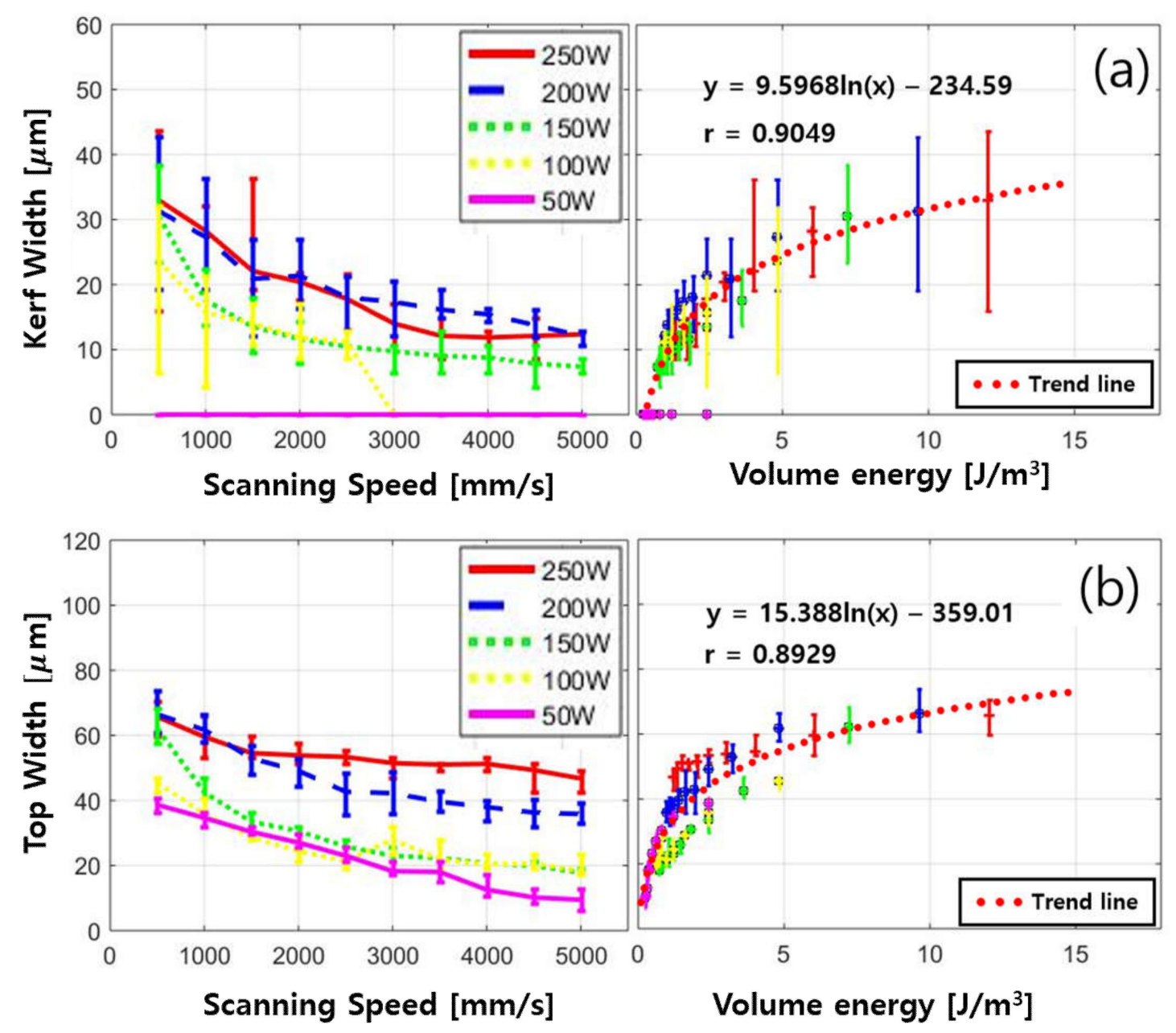

Figure 7. Comparison of (a) kerf width and (b) top width of the uncompressed cathode.

The relationship between the volume energy and the kerf width as well as the volume energy and the top width are shown in Figure 7 (right) with trend lines. The kerf width and the top width are dependent on the volume energies. Furthermore, an increase in volume energy causes a logarithmic increase in the kerf width and the top width. The correlation coefficient of the kerf width is 0.9049 and the correlation coefficient of the top width is 0.8929 . Since it is rather close to 1 , it was indicated that the variables are positively logarithmically related.

Figure 8 shows the average values of energy required to remove cathodes. This is obtained by Equation (5). Remove energy decreases exponentially as increasing scanning speed for all laser powers. Remove energy also decreases when the laser power decreases. In addition, remove energy logarithmically increases as the volume energy increases. Unlike the compressed cathode, the remove energy required for the uncompressed cathode depends on laser intensity and interaction time.

Figure 9 shows SEM images with the laser power of $250 \mathrm{~W}$. Figure $9 \mathrm{a}$ is the top view and Figure $9 \mathrm{~b}$ is the cross-section view. The melting width is not formed as shown in Figure 9a and it is invisible to all cut samples used in this study. Thus, no clearance width can be seen. 

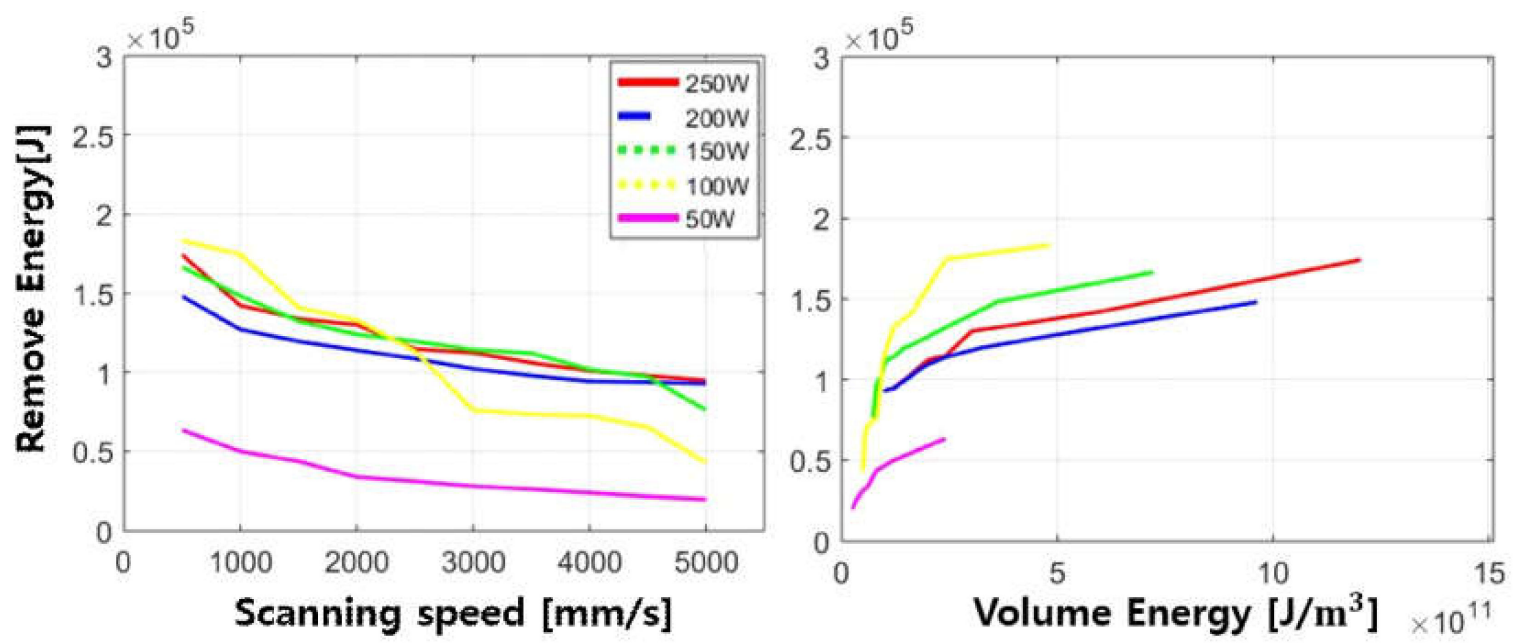

Figure 8. Comparison of removal energy for the uncompressed cathode.
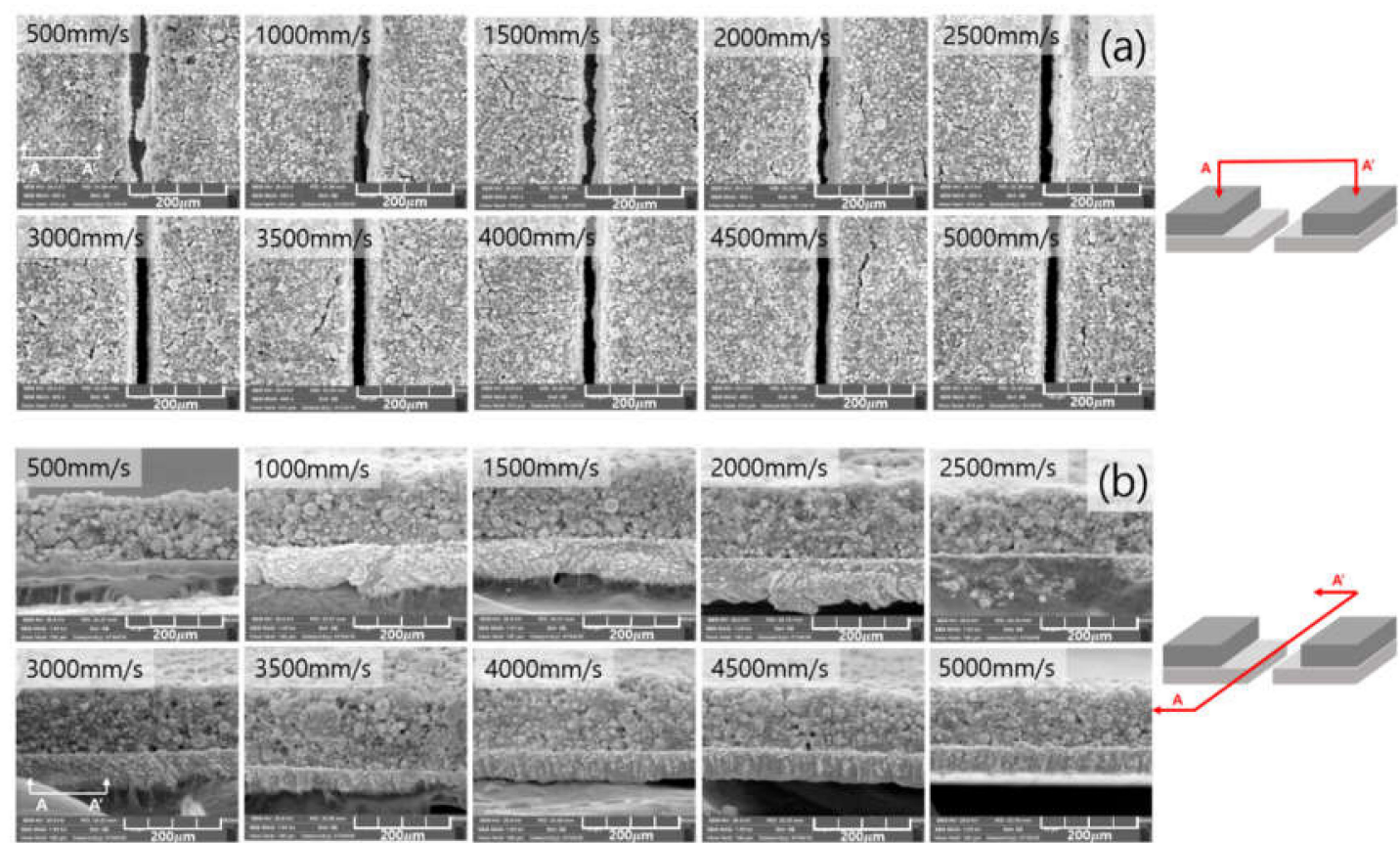

Figure 9. SEM images of uncompressed cathode with the laser power of $250 \mathrm{~W}$, (a) Top view (b) Cross-section.

For the cathodes cut at the scanning speed of $500 \mathrm{~mm} / \mathrm{s}$ to $2000 \mathrm{~mm} / \mathrm{s}$, the kerf width is not uniform as shown in Figure 9a. Likewise, from the scanning speed $500 \mathrm{~mm} / \mathrm{s}$ to $2000 \mathrm{~mm} / \mathrm{s}$, the cross-section of the current collector was not a clean surface, because the current collector was re-solidified. Thus, excessive cutting is observed with the laser cutting of $500 \mathrm{~mm} / \mathrm{s}$ to $2500 \mathrm{~mm} / \mathrm{s}$. At the scanning speed of $2500 \mathrm{~mm} / \mathrm{s}$, no delamination or aluminum beads were observed while the striation marks and spherical particles are observed. From the scanning speed of $3500 \mathrm{~mm} / \mathrm{s}$ to $5000 \mathrm{~mm} / \mathrm{s}$, high-quality cut, or proper cutting, can be observed as shown in Figure 10. No delamination, no striation, and no aluminum beads were formed while the $\mathrm{LiFePO}_{4}$ in the formed of the spherical particle is still observed. This is similar to the results seen in the compressed cathode. 


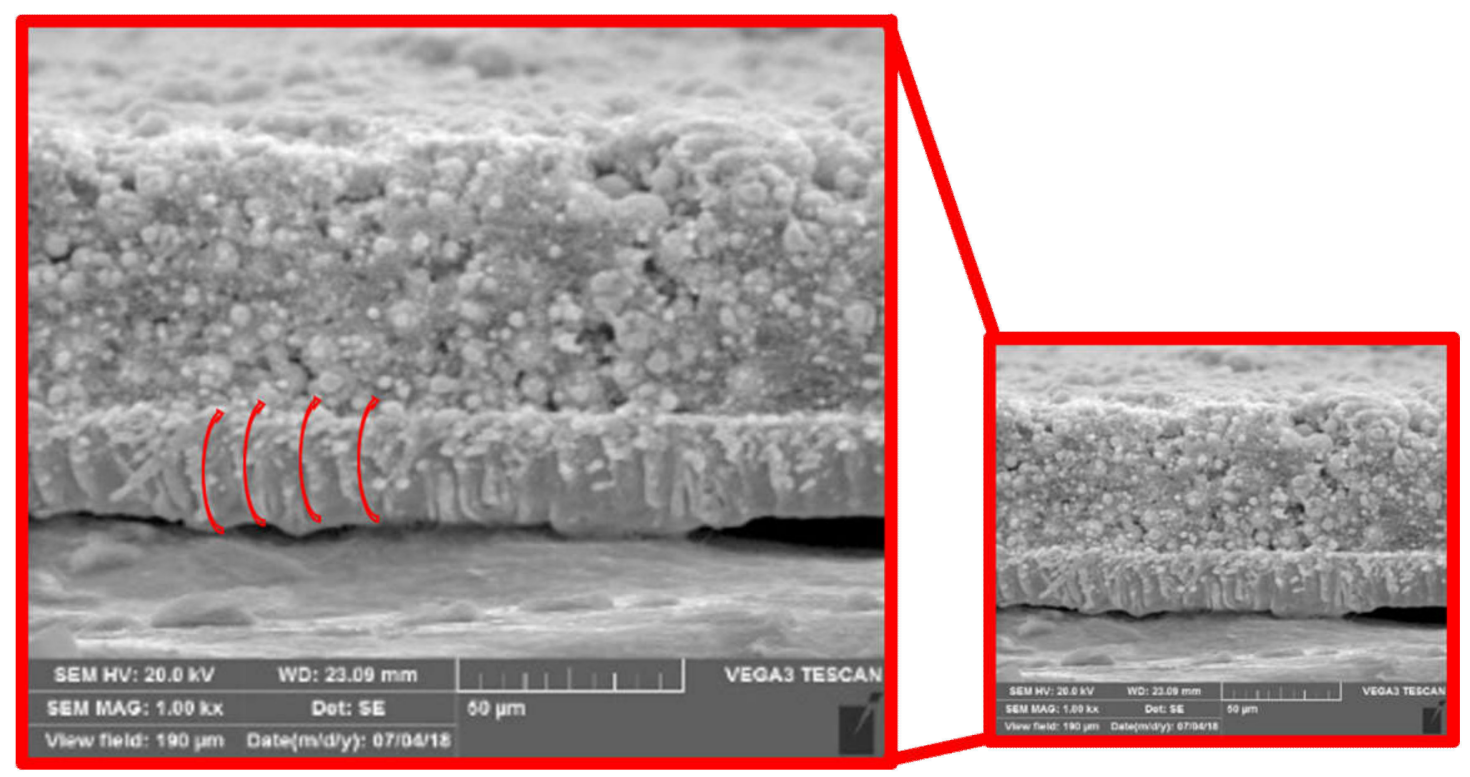

Figure 10. The cross-section of the uncompressed cathode with the scanning speed of $4000 \mathrm{~mm} / \mathrm{s}$.

\subsection{Comparison of Compressed and Uncompressed Cathode: Cutting Configuration, Cutting Region, Absorption Rate, Composition Change}

To compare the compressed and uncompressed cathodes, we presented cutting configuration, cutting region, absorption rate, and composition change. Cutting configuration is obtained by observing the kerf and top widths. The cutting region is classified based on previous studies $[13,14]$. Absorption rate is measured from the wavelength of $200 \mathrm{~nm}$ to $2400 \mathrm{~nm}$. Composition change is measured by SEM and EDX along with cross-section.

Figure 11a shows the comparison of kerf width between compressed and uncompressed cathodes with respect to scanning speed with the laser power of $250 \mathrm{~W}$. The width of the laser power of $250 \mathrm{~W}$ is chosen because it clearly shows differences between compressed and uncompressed cathodes.
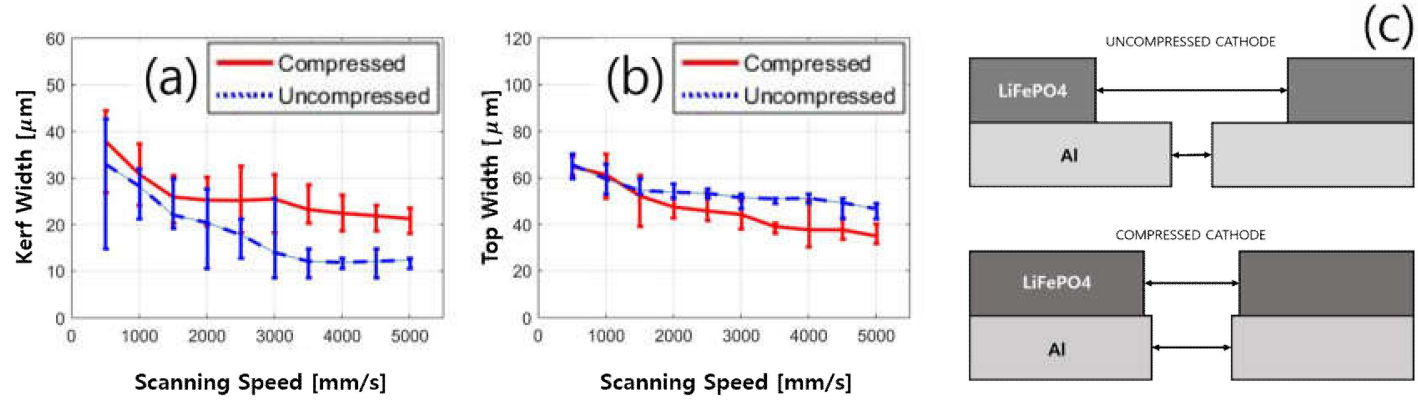

Figure 11. Comparison of (a) Kerf width, (b) Top width, and (c) Cutting configuration with the laser power of $250 \mathrm{~W}$.

The kerf widths of the uncompressed cathode (blue) are narrower than those of compressed cathode. Figure $11 \mathrm{~b}$ shows the comparison of the top widths with respect to the scanning speed. It is observed that the top widths of the compressed cathode (red) are narrower than the top widths of the uncompressed cathode. According to measured data of the kerf width and top width, a configuration of the cutting is shown in Figure 11c. The difference between the kerf width and top width of the compressed cathode is smaller than the difference between the kerf width and top width of the uncompressed cathode. When compressed, cathodes suffer deformation caused by the change in the average relative position of its atoms and molecules. $\mathrm{LiFePO}_{4}$ is contracted in volume by compression, and the total volume of the compressed $\mathrm{LiFePO}_{4}$ is decreased. Therefore, the density per unit volume 
of the compressed $\mathrm{LiFePO}_{4}$ is increased. Increasing density increases the energy required for material removal, as described in Equation (5). As a result, compressed cathodes require a higher volume of energy to remove the unit volume. Since higher energy is required for the compressed cathode to fully remove the $\mathrm{LiFePO}_{4}$ and higher density, the ratio of longitudinal heat transfer to transverse heat transfer for the compressed cathode is higher than the ratio for the uncompressed cathode. Therefore, a narrower top width and wider kerf width of the compressed cathode can be obtained. From the manufacturing perspective, the compressed cathode may provide more efficient laser cutting compared to the uncompressed cathode. From the battery performance perspective, the thickness and loading level of the cathode are the key factors to increase the energy of the battery. However, high loading level and increasing thickness can lead to power limitations and poor rate capability. To balance the performance, it is necessary to modify the formulation of slurry. For example to change the ratio of active materials, binder and conductive carbon materials help to improve the lithium-ion diffusion kinetics. Phase change during thermal driven laser cutting may lead to battery performance deterioration. The thermal driven laser cutting may melt the polymer binder. However, $\mathrm{LiFePO}_{4}$ and conductive carbon powder in the electrode do not undergo chemical modifications or phase change during laser cutting.

Cutting regions with the SEM images are shown in Figure 12. The observed SEM images are classified by five regions: (1) Proper ablation region, (2) Excessive ablation region, (3) Defective cutting region, (4) Proper cutting region, (5) Excessive cutting region. First, the proper ablation region (Figure 12a) is assigned when the active electrode material is completely removed from the target region without melting the current collector. Second, the excessive ablation region (Figure 12b) is assigned when the active electrode material is removed and the melting of the current collector is observed. Third, the defective cutting region (Figure 12c) is assigned when the active electrode material is completely removed and the current collector is partially penetrated or cut in the target region. Forth, the proper cutting region (Figure 12d) is assigned when the active electrode material and the current collector are uniformly removed. Finally, the excessive cutting region (Figure 12e) is assigned when the current collector is melted and re-solidified, so that the kerf width is not uniform. Moreover, delamination can be observed due to the high recoil pressure.

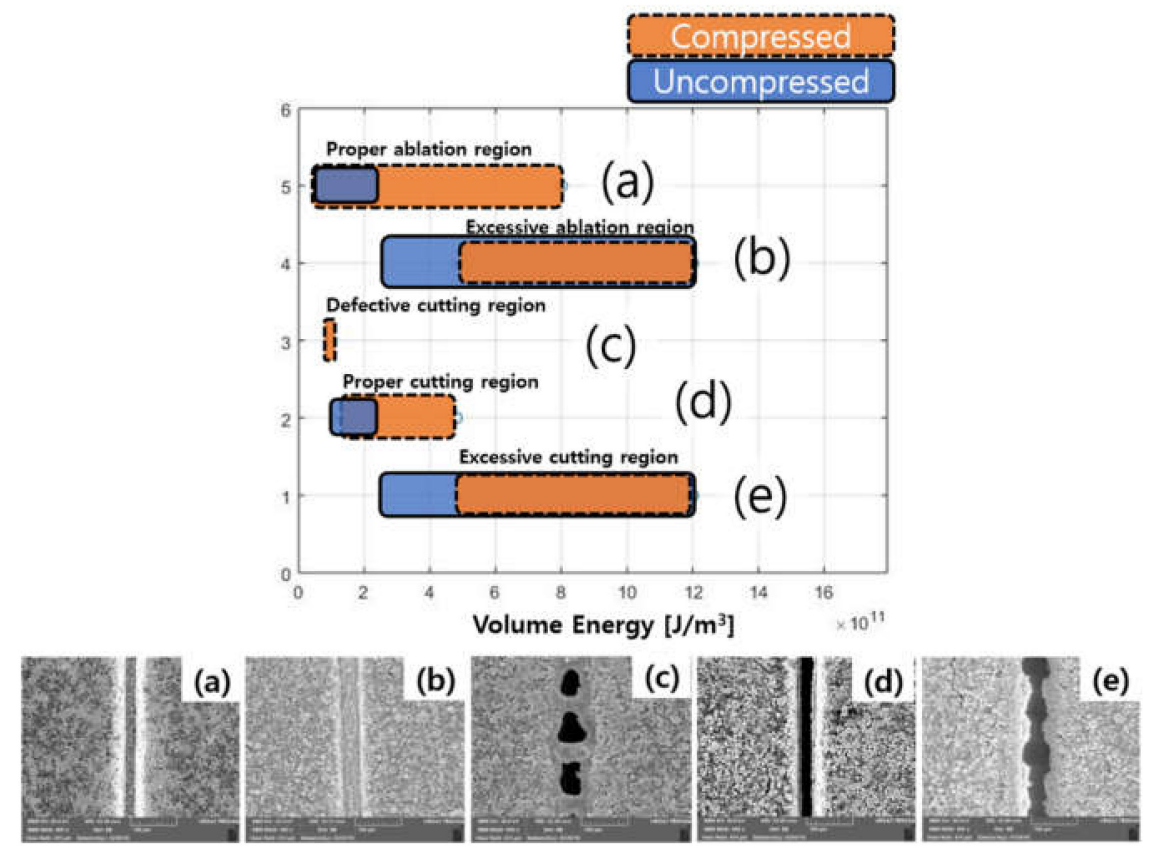

Figure 12. Category and volume energy of cutting region depending on five physical phenomena. (a) Proper ablation region; (b) Excessive ablation region; (c) Defective cutting region; (d) Proper cutting region; (e) Excessive cutting region. 
The classification and comparison in terms of the volume energy are shown in Figure 12 (top). The proper ablation region and the proper cutting region of the compressed cathode are wider than the uncompressed cathode. However, the excessive ablation region and the excessive cutting region of the uncompressed cathodes is wider than the compressed cathodes. According to this comparison, we can insist that the proper laser cutting of the compressed cathode can be obtained with wider volume energy. In addition, since the compressed cathode provides a wider range of volume energy for the proper ablation, the laser ablation of the compressed cathode is more easily applicable for the mass production to selectively remove or pattern $[43,44]$ the active electrodes.

Figure 13 shows the comparison of absorption rate of the compressed and uncompressed cathodes. If the compressed and uncompressed cathodes had a difference in absorption, interaction characteristics and material removal mechanism may be affected by this and the difference should be considered for the analysis. Hence, the absorptivity of compressed and uncompressed cathodes is compared with the wavelength of $1070 \mathrm{~nm}$. The compressed cathode has an absorptivity of $97.22 \%$ while the uncompressed cathode has an absorptivity of $97.30 \%$. As a result, the difference of the absorption rate between compressed and uncompressed cathodes is $0.08 \%$. The compression of cathode does not significantly affect the absorptivity of the cathode. Therefore, we can verify that the compression, or density change, of the active electrode material is the only factor to affect laser cutting characteristics.

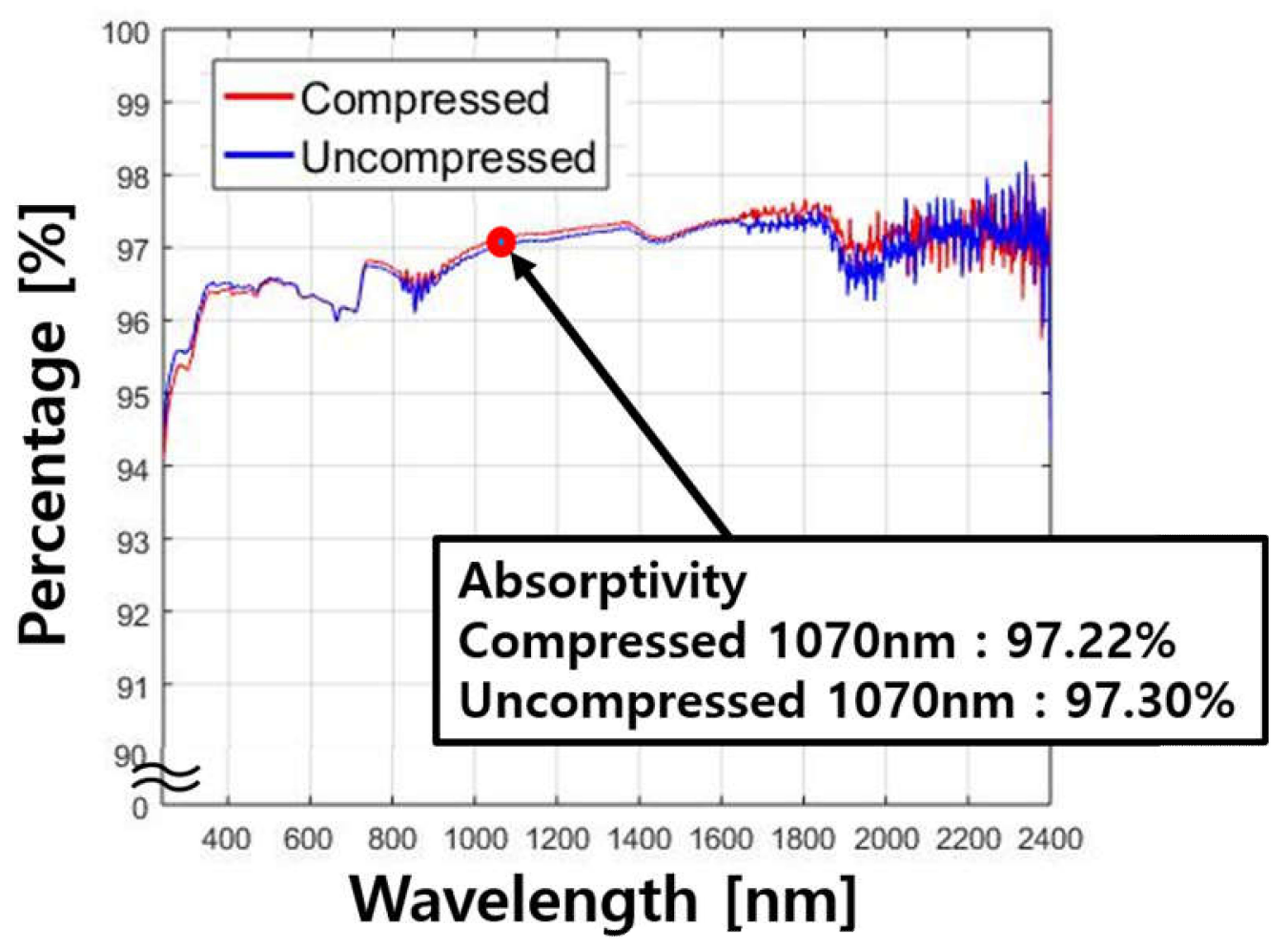

Figure 13. Compressed and Uncompressed cathodes' absorption rate.

The EDX analysis of the cathode material is shown in Figure 14. Figure 14 clearly shows the aluminum composition in the cathode cross-section. The boundary line refers to the thickness $(20 \mu \mathrm{m})$ of the current collector. The composition is measured from the bottom of the current collector to the top of active electrode material. Figure 14a shows the cross-section of compressed cathodes. The cathodes are cut by laser (top) and by mechanical cutting (bottom). It is cut by two methods, or laser and mechanical cutting, not only to investigate the effect of compression, but also to compare traditional mechanical cutting. For the compressed cathodes, the mechanically cut cathode gradually decreases its aluminum content from the current collector area, but the aluminum content decreases dramatically at the boundary line in the laser-cut cathode. The laser cut of the uncompressed cathode shows a gradual 
decrease in the aluminum content, as shown in Figure 14b. The aluminum content of the laser-cut cathode starts to decrease with $10 \mu \mathrm{m}$ offset from the boundary line to the surface of the active electrode material. In the mechanical cutting, the aluminum content is gradually reduced before the boundary line, as is the case with the compressed cathode specimen.
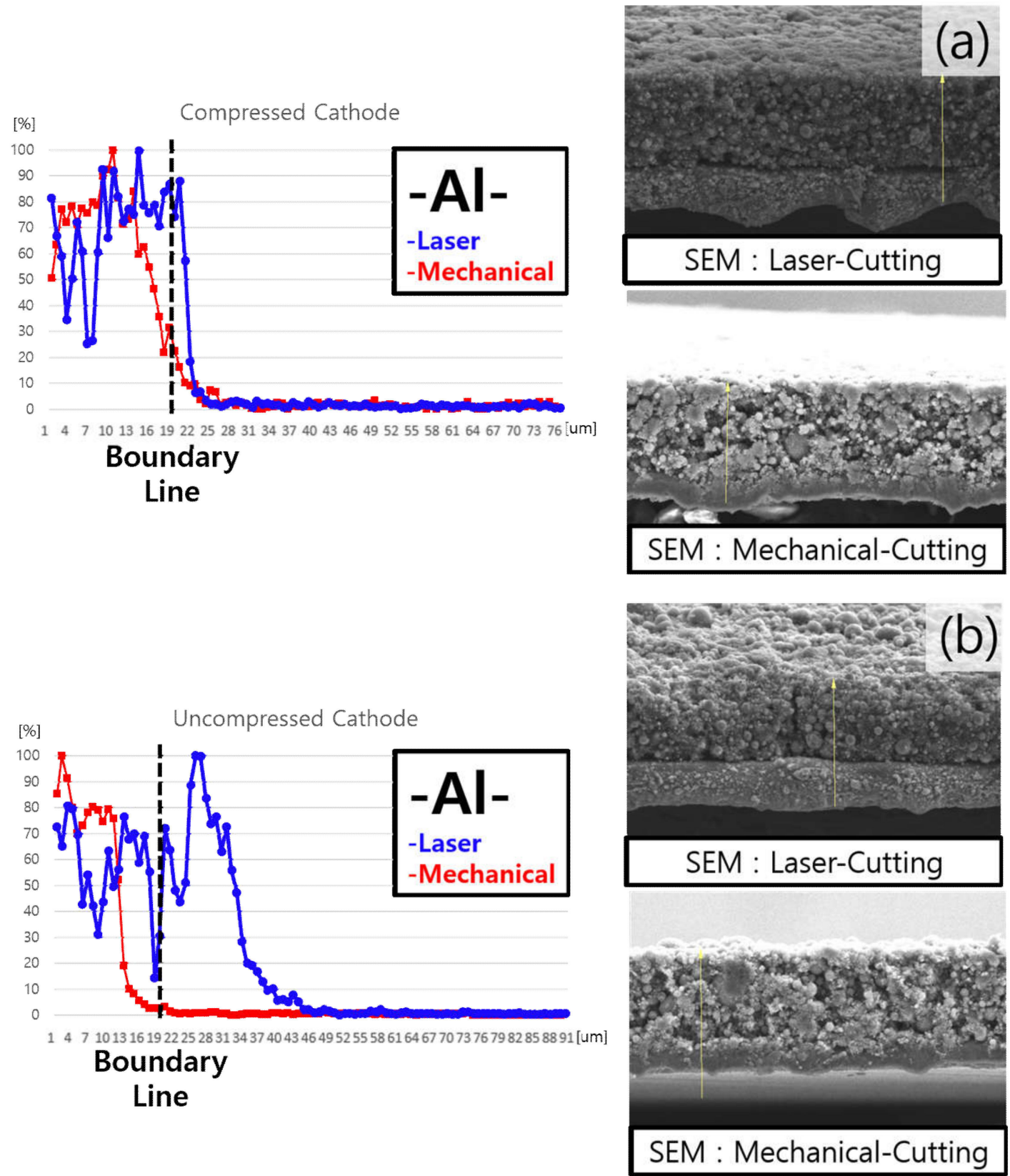

Figure 14. Comparison of composition changes for laser and mechanical cut of (a) compressed cathodes $(\mathrm{P}=250 \mathrm{~W}, \mathrm{v}=1000 \mathrm{~mm} / \mathrm{s})$ and $(\mathbf{b})$ uncompressed cathodes $(\mathrm{P}=250 \mathrm{~W}, \mathrm{v}=1000 \mathrm{~mm} / \mathrm{s})$.

The SEM images, as shown in Figure 14, also verify the EDX analysis that the cross-section of the mechanical cut is vague in the boundaries, while the laser cut cathode has a clearly defined current collector layer. From this observation, the active electrode material is crushed by the mechanical cutting. However, laser cutting shows a clear boundary between the active electrode material and current collector. In addition, the active electrode material is less contaminated by the current collector for compressed cathode. 


\section{Conclusions}

While Lithium-Ion Batteries (LIB) are growing in popularity for many applications, research considering the effects of electrodes' chemical, physical, and geometrical characteristics on the laser cutting remains rare. Hence, this study proposes the effect of compression of cathode on laser cutting for lithium-ion batteries and subsequently derives four main conclusions. First, increasing volume energy causes logarithmic increases in the kerf and top width for both compressed and uncompressed cathodes. Second, the differences between compressed and uncompressed cathodes after laser cutting are clear. The compressed cathode forms a wider kerf width than the uncompressed cathode under the same laser parameters. In addition, the top width of the uncompressed cathode is wider than the uncompressed cathode. Third, the compression has a favorable effect on uniform cutting and selective removal of active electrode materials, as well as widening the process window of the proper cutting and proper ablation. Finally, the compressed cathode shows a clear boundary between the active electrode and current collector. However, the active electrode region is contaminated by aluminum when the uncompressed cathode is used. In addition, the active electrode materials of both the compressed and uncompressed cathodes are crushed by mechanical cutting.

Author Contributions: D.L. and J.S. conceived and designed the experiments; D.L. and J.S. performed the experiments; D.L. and B.O. analyzed the data; D.L. and J.S. contributed reagents/materials/analysis tools; D.L., B.O., and J.S. wrote the paper.

Funding: The research described herein was sponsored by the National Research Foundation of Korea (NRF) grant funded by the Korean government (MSIP; Ministry of Science, ICT \& Future Planning) (No. 2017R1C1B5017916). This work is also supported by the Government-funded Research Program (KK1702). The opinions expressed in this paper are those of the authors and do not necessarily reflect the views of the sponsors.

Conflicts of Interest: The authors declare no conflicts of interest.

\section{References}

1. Giuli, G.; Eisenmann, T.; Bresser, D.; Trapananti, A.; Asenbauer, J.; Mueller, F.; Passerini, S. Structural and Electrochemical Characterization of $\mathrm{Zn}_{1-x} \mathrm{Fe}_{x} \mathrm{O}-$ Effect of Aliovalent Doping on the $\mathrm{Li}^{+}$Storage Mechanism. Materials 2018, 11, 49. [CrossRef] [PubMed]

2. Wang, Z.; Zhang, X.; Zhang, Y.; Li, M.; Qin, C.; Bakenov, Z. Chemical Dealloying Synthesis of CuS Nanowire-on-Nanoplate Network as Anode Materials for Li-Ion Batteries. Metals 2018, 8, 252. [CrossRef]

3. Yuan, G.; Xiang, J.; Jin, H.; Wu, L.; Jin, Y.; Zhao, Y. Anchoring ZnO Nanoparticles in Nitrogen-Doped Graphene Sheets as a High-Performance Anode Material for Lithium-Ion Batteries. Materials 2018, 11, 96. [CrossRef] [PubMed]

4. Suk, J.; Lee, Y.H.; Kim, D.Y.; Kim, D.W.; Cho, S.Y.; Kim, J.M.; Kang, Y. Semi-interpenetrating solid polymer electrolyte based on thiol-ene cross-linker for all-solid-state lithium batteries. J. Power Sources 2016, 334, 154-161. [CrossRef]

5. Ding, Y.-L.; Wen, Y.; Wu, C.; van Aken, P.A.; Maier, J.; Yu, Y. 3D V ${ }_{6} \mathrm{O}_{13}$ Nanotextiles Assembled from Interconnected Nanogrooves as Cathode Materials for High-Energy Lithium Ion Batteries. Nano Lett. 2015, 15, 1388-1394. [CrossRef] [PubMed]

6. Nitta, N.; Wu, F.; Lee, J.T.; Yushin, G. Li-ion battery materials: Present and future. Mater. Today 2015, 18, 252-264. [CrossRef]

7. Suk, J.; Kim, D.Y.; Kim, D.W.; Kang, Y. Electrodeposited 3D porous silicon/copper films with excellent stability and high rate performance for lithium-ion batteries. J. Mater. Chem. A 2014, 2, 2478-2481. [CrossRef]

8. Chen, J. Recent Progress in Advanced Materials for Lithium Ion Batteries. Materials 2013, 6, 156-183. [CrossRef] [PubMed]

9. Ogihara, T.; Kodera, T. Synthesis of $\mathrm{Li}_{2} \mathrm{Ti}_{3} \mathrm{O}_{7}$ Anode Materials by Ultrasonic Spray Pyrolysis and Their Electrochemical Properties. Materials 2013, 6, 2285-2294. [CrossRef] [PubMed]

10. Jo, M.; Yoo, H.; Jung, Y.S.; Cho, J. Carbon-coated nanoclustered $\mathrm{LiMn}_{0.71} \mathrm{Fe}_{0.29} \mathrm{PO}_{4}$ cathode for lithium-ion batteries. J. Power Sources 2012, 216, 162-168. [CrossRef]

11. Lee, D.; Mazumder, J. Dataset demonstrating effects of momentum transfer on sizing of current collector for lithium-ion batteries during laser cutting. Data Brief 2018, 17, 6-14. [CrossRef] [PubMed] 
12. Lee, D.; Mazumder, J. Effects of momentum transfer on sizing of current collectors for lithium-ion batteries during laser cutting. Opt. Laser Technol. 2018, 99, 315-325. [CrossRef]

13. Lee, D. Investigation of Physical Phenomena and Cutting Efficiency for Laser Cutting on Anode for Li-Ion Batteries. Appl. Sci. 2018, 8, 266. [CrossRef]

14. Lee, D.; Ahn, S. Investigation of Laser Cutting Width of $\mathrm{LiCoO}_{2}$ Coated Aluminum for Lithium-Ion Batteries. Appl. Sci. 2017, 7, 914. [CrossRef]

15. Lee, D.; Patwa, R.; Herfurth, H.; Mazumder, J. Parameter optimization for high speed remote laser cutting of electrodes for lithium-ion batteries. J. Laser Appl. 2016, 28, 022006. [CrossRef]

16. Lee, D.; Patwa, R.; Herfurth, H.; Mazumder, J. Three dimensional simulation of high speed remote laser cutting of cathode for lithium-ion batteries. J. Laser Appl. 2016, 28, 032010. [CrossRef]

17. Lee, D.; Patwa, R.; Herfurth, H.; Mazumder, J. High speed remote laser cutting of electrodes for lithium-ion batteries: Anode. J. Power Sources 2013, 240, 368-380. [CrossRef]

18. Lee, D.; Patwa, R.; Herfurth, H.; Mazumder, J. Computational and experimental studies of laser cutting of the current collectors for lithium-ion batteries. J. Power Sources 2012, 210, 327-338. [CrossRef]

19. Kronthaler, M.R.; Schloegl, F.; Kurfer, J.; Wiedenmann, R.; Zaeh, M.F.; Reinhart, G. Laser Cutting in the Production of Lithium Ion Cells. Phys. Procedia 2012, 39, 213-224. [CrossRef]

20. Lee, D.; Seo, Y.; Pyo, S. Effect of Laser Speed on Cutting Characteristics of Cement-Based Materials. Materials 2018, 11, 1055. [CrossRef]

21. Lee, D. Experimental Investigation of Laser Ablation Characteristics on Nickel-Coated Beryllium Copper. Metals 2018, 8, 211. [CrossRef]

22. Lee, D.; Pyo, S. Experimental Investigation of Multi-mode Fiber Laser Cutting of Cement Mortar. Materials 2018, 11, 278. [CrossRef] [PubMed]

23. Lee, D. Investigation of Laser Ablation on Acrylonitrile Butadiene Styrene Plastic Used for 3D Printing. J. KWJS 2018, 36, 50-56.

24. Lee, D. Picosecond IR Pulsed Laser Drilling of Copper-Coated Glass/Epoxy Composite. IEEE Trans. Compon. Packag. Manuf. Technol. 2017, 7, 2066-2072. [CrossRef]

25. Lee, D.; Cho, J.; Kim, C.H.; Lee, S.H. Application of laser spot cutting on spring contact probe for semiconductor package inspection. Opt. Laser Technol. 2017, 97, 90-96. [CrossRef]

26. Lee, D. Experimental Investigation of Laser Spot Welding of Ni and Au-Sn-Ni Alloy. J. Weld. Join. 2017, 35, 1-5. [CrossRef]

27. Lee, D.; Mazumder, J. Effects of laser beam spatial distribution on laser-material interaction. J. Laser Appl. 2016, 28, 032003. [CrossRef]

28. Lee, D. Modeling of High Speed Remote Laser Cutting for Lithium-Ion Batteries; Scholar's Press: Riga, Latvia, 2016.

29. Lee, D.; Bae, K.M.; Suk, J. Experimental Study of Laser Cutting on Uncompressed $40 \mu$ m-thick Anode for Lithium-Ion Batteries. Opt. Laser Technol. 2018. under review.

30. Lutey, A.H.A.; Fortunato, A.; Carmignato, S.; Fiorini, M. High speed pulsed laser cutting of $\mathrm{LiCoO}_{2} \mathrm{Li}_{-}$ion battery electrodes. Opt. Laser Technol. 2017, 94, 90-96. [CrossRef]

31. Spena, P.R. $\mathrm{CO}_{2}$ Laser Cutting of Hot Stamping Boron Steel Sheets. Metals 2017, 7, 456. [CrossRef]

32. Rodrigues, G.C.; Duflou, J.R. Into polarization control in laser cutting with direct diode lasers. J. Laser Appl. 2016, 28, 022207. [CrossRef]

33. Daniel, C.; Ostendorf, S.; Hallmann, S.; Emmelmann, C. Picosecond laser processing of polycrystalline cubic boron nitride-A method to examine the ablation behavior of a high cubic boron nitride content grade material. J. Laser Appl. 2016, 28, 012001. [CrossRef]

34. Demir, A.G.; Previtali, B. Dross-free submerged laser cutting of AZ31 Mg alloy for biodegradable stents. J. Laser Appl. 2016, 28, 032001. [CrossRef]

35. Herzog, D.; Schmidt-Lehr, M.; Oberlander, M.; Canisius, M.; Radek, M.; Emmelmann, C. Laser cutting of carbon fibre reinforced plastics of high thickness. Mater. Des. 2016, 92, 742-749. [CrossRef]

36. Hilton, P.A.; Lloyd, D.; Tyrer, J.R. Use of a diffractive optic for high power laser cutting. J. Laser Appl. 2016, 28, 012014. [CrossRef]

37. Ghavidel, A.K.; Navidfar, A.; Shabgard, M.; Azdast, T. Role of $\mathrm{CO}_{2}$ laser cutting conditions on anisotropic properties of nanocomposite contain carbon nanotubes. J. Laser Appl. 2016, 28, 032006. [CrossRef] 
38. Kim, D.-H.; Lee, C.-M. A study on the laser-assisted ball-end milling of difficult-to-cut materials using a new back-and-forth preheating method. Int. J. Adv. Manuf. Technol. 2016, 85, 1825-1834. [CrossRef]

39. Lutey, A.H.A.; Fortunato, A.; Ascari, A.; Carmignato, S.; Leone, C. Laser cutting of lithium iron phosphate battery electrodes: Characterization of process efficiency and quality. Opt. Laser Technol. 2015, 65, 164-174. [CrossRef]

40. Luetke, M.; Franke, V.; Techel, A.; Himmer, T.; Klotzbach, U.; Wetzig, A.; Beyer, E. A Comparative Study on Cutting Electrodes for Batteries with Lasers. Phys. Procedia 2011, 12 Pt 2, 286-291. [CrossRef]

41. Reincke, T.; Kreling, S.; Dilger, K. The influences of pulse overlap on cut quality during fiber laser cutting of electrodes for Lithium-ion batteries. In Proceedings of the Lasers in Manufacturing Conference, Berlin, Germany, 22-25 June 2015; pp. 22-25.

42. Jansen, T.; Blass, D.; Hartwig, S.; Dilger, K. Processing of Advanced Battery Materials—Laser Cutting of Pure Lithium Metal Foils. Batteries 2018, 4, 37. [CrossRef]

43. Hirokazu, M.; Kazuomi, Y.; Kiyoshi, K. Fabrication of 3D patterned electrodes for micro lithium-ion batteries. IOP Conf. Ser. 2011, 18, 122007.

44. Choi, S.; Lee, J.-I.; Park, S. Patterning of electrodes for mechanically robust and bendable lithium-ion batteries. J. Mater. Chem. 2012, 22, 22366-22369. [CrossRef]

(C) 2019 by the authors. Licensee MDPI, Basel, Switzerland. This article is an open access article distributed under the terms and conditions of the Creative Commons Attribution (CC BY) license (http://creativecommons.org/licenses/by/4.0/). 